\title{
Assessment of efficiency of diesel generators use in distributed energy industry
}

\author{
Alexandr Alyunov ${ }^{1, *}$, Olga Vyatkina $^{1}$, Ivan Smirnov ${ }^{1}$, Alexandr Nemirovskiy ${ }^{1}$ and Elena Gracheva ${ }^{2}$ \\ ${ }^{1}$ Vologda State University, Lenina str. 15, Vologda, Russia \\ ${ }^{2}$ Kazan State Power Engineering University, Kazan, Russia
}

\begin{abstract}
The existing methods for calculation electricity tariffs for enterprises are analyzed numerically. The efficiency of diesel generators use for power supply was estimated using a real object as an example. A methodology has been developed for choosing the optimal price category, based on the schedule for consumption of electrical energy of a particular enterprise, taking into account introduction of its own generation in the $0.4 \mathrm{kV}$ network. It is shown how to get the maximum benefit using one of the most affordable and autonomous power sources, taking into account the peculiarities of tariff setting for electricity.
\end{abstract}

\section{Introduction}

In modern electric power industry, there is a problem of constant growth of electricity tariffs, under centralized electricity supply. Analysis of statistical data shows that the cost of electricity has grown more than five times for the final consumer, and it likely to grow further.

The introduction of own generation at industrial facilities is the most optimal solutions to the problem, both from practical and from economic points of view [1], [2].

As it is known, the main consumers of electricity are industrial enterprises, and a significant share of consumption is accounted by small and medium-sized enterprises, the installed capacities of which are in the range from several kilowatts to ten megawatts [3] - [5].

We evaluate the efficiency of distributed generation for small and medium-sized enterprises. For such enterprises it is inefficient to use large block stations, due to the lack of territory for their erection, as well as high costs of their construction and maintenance. Also, most enterprises do not have gas distribution stations, substations and main gas pipelines near them. One of the advantages of diesel power plants is the possibility of their widespread use, since diesel fuel is much more affordable than other types of fuel. We take into consideration this category of own generation [5] - [8].

The cost of a unit of electricity generated by a diesel generator is higher than the cost of a unit of electricity purchased from the network, for example, in the night. This is due to the relatively high cost of diesel fuel. Thus, the continuous use of diesel generators for autonomous power supply is disadvantageous. However, switching it on for certain periods of time, for example, during peak hours or hours of power take-off, can significantly reduce the cost of purchasing electricity.
The purpose of this work is:

1. To numerically analyze the existing methods for calculating electricity tariffs for enterprises (price categories).

2. To evaluate the efficiency of using diesel generators for power supply using an example of a real object.

3. To develop a methodology for selecting the optimal price category based on the schedule for consumption of electrical energy of a particular enterprise, taking into account the introduction of its own generation in a $0.4 \mathrm{kV}$ network.

\section{Materials and methods}

We consider the choice of optimal price category and assessment of efficiency of using diesel generators in a $0.4 \mathrm{kV}$ network using the example of a woodworking enterprise.

The initial data provided by the enterprise include:

- Volumes of electricity by feeder at hourly intervals for the billing period (we take into consideration the volumes of electricity for December 2019 [9]).

- The voltage side on which electricity is being purchased (for this enterprise).

In addition to the initial data the components of the maximum levels of unregulated prices and monthly reports on peak hours are required for the calculation of all price categories.

The price category is calculated according to the algorithm described in [10], with a detailed description of each component of the electricity price: the purchase price of electricity in the wholesale market; electricity transmission services; sales allowance. The need to account for all three components is due to the fact that they in total show approximately $98 \%$ of the final cost of

\footnotetext{
* Corresponding author: alyunov@mail.ru
} 
electricity for the consumer provided by the guaranteeing supplier. The calculation does not include value added tax. The results of the cost calculation are presented in table 1 .

The use of a diesel generator at the enterprise, when it is switched on during peak hours (hours for peak load monitoring), allows one to obtain a significant economic effect due to reduction in power cost. This is possible when calculating for the 3-6 price categories.

Thus, the task is reduced to the choice of optimal power and strategy of the diesel generator operation.

The correct choice of a diesel generator allows one to save significant money, due to different nominal flow characteristics.

We compare the cost of $1 \mathrm{~kW} \cdot \mathrm{h}$ of electricity generated by diesel generators of equal power, but from different manufacturers.

The cost of $1 \mathrm{~kW} \cdot \mathrm{h}$ of energy generated by a diesel generator is determined by the formula (1):

$$
S_{D}=\frac{Q_{D F} \cdot S_{D F}}{P_{W}}, \$ / \mathrm{kW} \cdot \mathrm{h},
$$

where $Q_{D F}$ is the diesel fuel consumption, $1 / \mathrm{h}$;

$S_{D F}$ is the diesel fuel price, $\$ / 1$;

$P_{W}$ is the rated power of the diesel generator, $\mathrm{kW}$;

$S_{D}$ is the cost of $1 \mathrm{~kW} \cdot \mathrm{h}$ of electricity generated by a diesel generator, $\$ / \mathrm{kW} \cdot \mathrm{h}$.

The calculations presented in [10] show that the cost of $1 \mathrm{~kW} \cdot \mathrm{h}$ of electricity generated by a diesel generator is in the range of $8-9 \$ / \mathrm{kW} \cdot \mathrm{h}$. For the first price category, this value is higher than the cost of electricity purchased from the network, therefore, the use of a diesel generator at the enterprise is disadvantageous. For the second price category, this value is higher if electricity is purchased at half-peak, night and day hours, but during peak hours load, the cost of electricity purchased from the network becomes higher than the cost of electricity generated by a diesel generator. Therefore, for the second price category, it is advantageous to turn on the diesel generator only during peak hours. If the calculations are carried out for the 3-6 price categories, then, as indicated above, the cost of electricity is determined for each hour separately, therefore, it is almost impossible to choose the hour at which the diesel generator must be put into operation in order to get a profit.

The greatest economic effect can be achieved by reducing the cost of power. To achieve this goal, it is necessary to simultaneously solve the problem of choosing the optimal power and strategy of the diesel generator.

Based on the studies presented in [3] - [8], we derive an algorithm for choosing the optimal price category taking into account the use of a diesel generator:

1. Initial data is entered: the volume of electricity at hourly intervals for the billing period, the voltage side, the amount of cash (that is, the amount that the customer is ready to allocate for the purchase of a diesel generator).
2. Calculation of the cost of electricity is performed for a price category without taking into account the diesel generator.

3. A load schedule is constructed during power takeoff hours for the working days of the month.

4. For peak hours of working days of month, the $X$ indicator is studied (the power at the $\mathrm{i}$-th hour of the $\mathrm{j}$-th working day), obtained as a result of measurements using mathematical statistics methods. The standard deviation of mean power $(\delta)$ and minimum power consumption (Pmin) are determined.

5 . The capacity of diesel generator $\left(P_{W}\right)$ is selected based on the amount of money allocated for its purchase in accordance with the condition (2):

$$
\delta \leq P_{W} \leq 2.5 \cdot P \min , \mathrm{kW},
$$

where $P \min$ is the minimum power consumption, $\mathrm{kW}$;

$\delta$ is the standard deviation from average power, $\mathrm{kW}$.

To determine the operation strategy of the diesel generator, the possible number of operation hours of the diesel generator per day $(t)$ is calculated. Most often, $t$ is equal to the number of peak hours.

In case the funds are insufficient to purchase the diesel generator of the required capacity, $P_{\mathrm{W}}$ can be determined from the condition (3).

$$
P_{W} \leq \delta, \mathrm{kW},
$$

Further the strategy of diesel generator is determined from the conditions of optimal reduction of the network power and power being paid in the wholesale electricity market.

6. The calculation of the cost of electricity by price category is carried out taking into account the work of diesel generator according to the developed strategy.

7. The efficiency of using one or another version of the diesel generator is evaluated.

\section{Results and discussions}

Using the developed algorithm, we calculate the cost of electricity for a woodworking enterprise.

According to conditions (2) - (3), we choose the power of diesel generator. We consider two possible options.

Option No. 1: Amperos AD 400-T400 diesel generator.

Option No. 2: TSS AD-200S-T400-1RKM11 diesel generator.

The possible amount of operation hours of the diesel generator per day $(\mathrm{t})$, taking into account data [5], is 12 .

The strategy for the December operation of a $200 \mathrm{~kW}$ diesel generator (option No. 2) during peak hours is 5 hours a day: from 8 am to 11 am and at $3 \mathrm{pm}$.

The strategy for the December operation of a $400 \mathrm{~kW}$ diesel generator (option No. 1) during peak hours is 12 hours a day: from 8 am to 12 am and from $3 \mathrm{pm}$ to $9 \mathrm{pm}$.

The results of calculating the cost of electricity are presented in table 1 . 
Table 1. Total prices by price categories for December 2019 when using diesel generators.

\begin{tabular}{|c|c|c|c|}
\hline 总 & 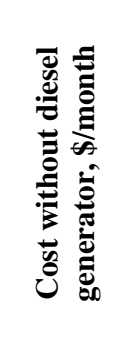 & 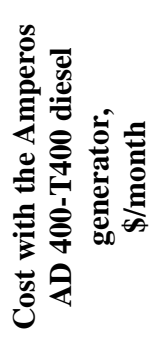 & 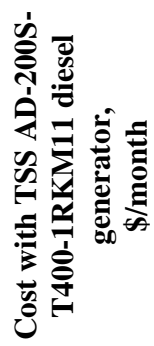 \\
\hline 1. PC1 & 53690 & 55000 & 56360 \\
\hline 2. $\mathrm{PC} 2 / 2$ & 59717 & 60356 & 60376 \\
\hline 3. PC $2 / 3$ & 65892 & 65613 & 64480 \\
\hline 4. PC3 & 51402 & 51592 & 52041 \\
\hline 5. PC4 & 50018 & 48273 & 46527 \\
\hline 6. PC5 (1.1) & 51296 & 51493 & 51685 \\
\hline 7. PC5 (0.9) & 51181 & 51381 & 51585 \\
\hline 8. PC5 (ideal) & 50968 & 51180 & 51409 \\
\hline 9. PC6 (1.1) & 49755 & 48026 & 46306 \\
\hline 10. PC6 (0.9) & 49641 & 47914 & 46203 \\
\hline $\begin{array}{l}11 . \text { PC6 } \\
\text { (ideal) }\end{array}$ & 49585 & 47862 & 46160 \\
\hline $\begin{array}{l}\text { Minimum } \\
\text { cost }\end{array}$ & 49585 & 47862 & 46160 \\
\hline Profit & 0 & 1722 & 3381 \\
\hline$T$, year & - & 0.81 & 0.75 \\
\hline
\end{tabular}

The payback period $(T)$ of both generators is approximately 10 months. However, the use of a $400 \mathrm{~kW}$ diesel generator is preferable, since monthly income is more important. The disadvantage of this solution is the high initial capital investment.

\section{Conclusions}

Analysis of the obtained results showed that the right choice of price category allows one to reduce energy costs by $30 \%$, and the introduction of own generation can further reduce these costs by $5-10 \%$.

\section{References}

[1] J.S. Savier, D. Das, Impact of Network Reconfiguration on Loss Allocation of Radial Distribution Systems, IEEE Trans. Power Del. 22, 4 (2007). DOI: 10.1109/TPWRD.2007.905370.

[2] V.V. Dubaylova, N.D. Mukhlynin, O.J. Polyakova, Distributed Generation Control in Energy Market Conditions Using Advanced Model Predictive Control 16th Conference on Electrical Machines, Drives and Power Systems (ELMA), Varna, Bulgaria, 1-4 (2019). DOI: 10.1109/ELMA.2019.8771696.

[3] S.A. Eroshenko, A.I. Khalyasmaa, The improvement of distributed generation integration efficiency, 11th IEEE International Conference on Compatibility, Power Electronics and Power Engineering, CPE-POWERENG (2017). DOI: 10.1109/CPE.2017.7915151.

[4] F.R.A. Bukit, N. Mubarakah, D.M. Nasution, Minimizing The Electrical Power Distribution Cost By
Optimizing the Distributed Generation Placement, 3rd International Conference on Electrical, Telecommunication and Computer Engineering (ELTICOM), Medan, Indonesia, 60-65 (2019). DOI: 10.1109/ELTICOM47379.2019.8943868.

[5] A.N. Alyunov, O.S. Vyatkina, I.G. Akhmetova, R.D. Pentiuc, K.E. Sakipov, Issues on optimization of operating modes of power transformers, E3S Web of Conferences 124, 02015 (2019) DOI: 10.1051/e3sconf/201912402015.

[6] A. Nemirovskiy, A. Kashin, V. Kosmach, Y. Titovec, I. Toptygin, D. Zaripova, Innovative technology for dismantling the windings of electric motors using ultrasonic radiation, IOP Conference Series: Earth and Environmental Science (EES) 337, 1, 012071 (2019). DOI: $10.1088 / 1755-1315 / 337 / 1 / 012071$.

[7] A.N. Egorov, Ya.S. Kharitonov, V.M. Khubieva, I.A. Yakushev, N.V. Golubtsov, Z.M. Shakurova, The impact of higher voltage and current harmonics on the operation of electrical systems, E3S Web of Conferences 124, 05067 (2019) DOI: https://doi.org/10.1051/e3sconf/201912405067

[8] Y.I. Gracheva, O.V. Naumov, Estimation of Power Losses in Electric Devices of the Electrotechnical Complex, International Conference on Industrial Engineering, Applications and Manufacturing, ICIEAM (2019). DOI: 10.1109/ICIEAM.2019.8742923.

[9] Trading System Administrator JSC: Components of limiting levels of unregulated prices [Electrical resource]. Available at: http:// www.atsenergo.ru.

[10] A.N. Alyunov, Web-service Online Electric [Electrical resource]. Available at: http://onlineelectric.ru. 